Volume 57

Issue 2 Winter 2008: Symposium - Challenges

to the Attorney-Client Relationship: Threats to

Article 2

Sound Advice?

\title{
Reflections on Juryphobia and Medical Malpractice Reform
}

Stephan Landsman

Follow this and additional works at: https://via.library.depaul.edu/law-review

\section{Recommended Citation}

Stephan Landsman, Reflections on Juryphobia and Medical Malpractice Reform, 57 DePaul L. Rev. 221 (2008)

Available at: https://via.library.depaul.edu/law-review/vol57/iss2/2

This Article is brought to you for free and open access by the College of Law at Digital Commons@DePaul. It has been accepted for inclusion in DePaul Law Review by an authorized editor of Digital Commons@DePaul. For more information, please contact digitalservices@depaul.edu. 


\title{
REFLECTIONS ON JURYPHOBIA AND MEDICAL MALPRACTICE REFORM
}

\author{
Stephan Landsman*
}

\section{INTRODUCTION}

In 1999, the Institute of Medicine (IOM) published a volume entitled To Err is Human. ${ }^{1}$ That report identified medical errors as one of the leading challenges facing medicine. ${ }^{2}$ The IOM's most headlinemaking conclusions were that as many as 98,000 hospitalized Americans die each year due to mistakes made by their caretakers and that hundreds of thousands more are injured during the course of treatment. ${ }^{3}$ The IOM noted that misadventure in hospitals was but one aspect of a far larger national medical error problem that also encompasses iatrogenic injury in outpatient facilities, nursing homes, and doctors' offices. ${ }^{4}$

Reaction to the IOM's report was swift and dramatic. Media attention was "frenzied," 5 and Congress scheduled hearings. ${ }^{6}$ President Clinton delivered a major address in February 2000, in which he endorsed a number of proposals from a federal interagency task force, declared a National Action Plan with the goal of cutting preventable

* Professor and Robert A. Clifford Chair in Tort Law and Social Policy, DePaul University College of Law. An earlier version of these materials was prepared for and presented at The University of Nebraska, which will be publishing them as a chapter in a volume entitled CIVIL Juries and Civil Justice (Brian Bornstein ed., 2008).

1. Committee on Quality of Health Care in america, Institute of Medicine, To Err is Human: Building a Safer Health System (Linda T. Kohn et al. eds., 2000) [hereinafter To ERr Is Human].

2. $I d$. at 26 . The concern about medical error grew steadily throughout the second half of the 1990 s, spurred by widely publicized malpractice horror stories, a series of high-profile conferences and the formation of an alliance of business and labor leaders dedicated to addressing the problem. See Paul Barach, The End of the Beginning: Lessons Learned from the Patient Safety Movement, 24 J. LEGAL MED. 7, 10-12 (2003).

3. To ERr Is Human, supra note 1, at 26.

4. Id. at 30-31; David A. Hyman \& Charles Silver, The Poor State of Health Care Quality in the U.S.: Is Malpractice Liability Part of the Problem or Part of the Solution?, 90 CornelL L. REv. 893, 903-04 (2005).

5. See David H. Johnson \& David W. Shapiro, The Institute of Medicine Report on Reducing Medical Error and Its Implications for Healthcare Providers and Attorneys, 12 HeAlTh LAW. 1, 1 (2000).

6. See Hearing on Medical Errors Before the Subcomm. on Health of the H. Comm. on Ways \& Means, 106th Cong. (2000); see also Barach, supra note 2, at 12. 
medical error-related deaths by $50 \%$ in five years, announced the promulgation of new regulations affecting the 6,000 hospitals across the nation that received Medicare funds, and called for the creation of a nationwide, state-based reporting system with both mandatory and voluntary components. ${ }^{7}$ Before his speech, the President had directed federal agencies to begin an effort to implement the IOM's proposals. ${ }^{8}$

Policymakers have proposed a variety of reforms to deal with the challenge of medical error. Although they advanced many before the IOM released its report, that document gave virtually all proposals at least a temporary boost. The thrust of many of these reforms has been to reduce medical mistakes and the harm they cause through disclosure of errors to either health professionals or patients. There have been essentially two objectives: first, to prevent future treatment errors; and second, to address injuries already suffered by patients. Among the preventive measures, policymakers have most frequently urged the collection, analysis, and reporting of large bodies of data concerning treatment mistakes. ${ }^{9}$ There has been considerable debate about precisely what sort of data should be the focus of such efforts. Some have called for concentration on sentinel or catastrophic events that result in death or serious injury to patients. ${ }^{10}$ Others have proposed the identification and review of all events that cause patient injury. ${ }^{11}$ Still others, taking a page from the book of the civil aviation industry, urge the identification and recording of "near misses"events that did not result in harm but could have under slightly different circumstances. ${ }^{12}$ Reformers view the gathering and reporting of data of any of these types as a stepping-stone to analysis that can pinpoint risks in the delivery of medical care and lead to the development of protocols that can prevent injury. ${ }^{13}$

Most prominent among the proposals designed to address injured patients' needs are those calling for more candid communications be-

7. William Clinton, Remarks by the President on Medical Errors (Feb. 22, 2000), available at http:/www.ahrq.gov/wh22200rem.htm; see also Johnson \& Shapiro, supra note 5, at 5.

8. See Barach, supra note 2, at 12.

9. See id. at 18; Barry R. Furrow, Medical Mistakes: Tiptoeing Toward Safety, 3 Hous. J. Health L. \& Pol'y 181, 182 (2003).

10. See Furrow, supra note 9, at 203 (discussing the IOM proposal); id. at 207 (describing the Joint Commission on Accreditation of Healthcare Organizations Sentinel Event Policy).

11. Id. at 213 (detailing Pennsylvania's legislative approach).

12. On aviation near-miss reporting, see Barach, supra note 2, at 20-21. On medical use of the near-miss approach, see Hyman \& Silver, supra note 4, at 931.

13. See Bryan A. Liang \& Steven D. Small, Communicating About Care: Addressing FederalState Issues in Peer Review and Mediation to Promote Patient Safety, 3 Hous. J. Health L. \& Pol'y 219, 225 (2003). 
tween healthcare professionals and patients who have been injured in their care. ${ }^{14}$ Building on this notion, some reformers have urged that, whenever medical error is discovered, the caregivers should apologize and, in at least some contexts, seek to negotiate an appropriate compensatory settlement. ${ }^{15}$

With so many interested players calling for change and advancing so many reform proposals, it is striking how little actual reform has been accomplished and how much the medical community has resisted modest changes and proposals. ${ }^{16}$ In fact, the major push from within the medical establishment has not been for internal changes to address medical errors, but rather for capped damage awards for those most severely injured by medical malpractice, as classified by the legal system. ${ }^{17}$ The futility of this step in responding to the incidence of medical malpractice and its tragic discriminations against children and the elderly have been frequently examined and will not be the focus of this Article. ${ }^{18}$ It should be noted, however, that the cap movement provides an insight into the healthcare industry's virtually singleminded preoccupation with lawsuits and large monetary awards whenever the question of error arises. This Article refers to that preoccupation as "juryphobia," because the fear of jury action that appears to be at its core has been the healthcare industry's primary justification for resisting reform. This Article begins with an examination of the rhetoric of juryphobia and its impact on reform proposals. It then suggests the utility of an empirical examination testing the claims of those who fear that change will lead to a massive increase in the number and size of malpractice jury awards. It concludes by considering curative steps that might be taken to counter hypothesized adverse jury reactions to reform.

14. See Keith Myers, Medical Errors: Causes, Cures, and Capitalism, 16 J.L. \& HeAlth 255, 278 (2002); Furrow, supra note 9, at 207.

15. See generally Jonathan R. Cohen, Apology and Organizations: Exploring an Example from Medical Practice, 27 Fordham Urb. L.J. 1447 (2000).

16. See D.E. Altman et al., Improving Patient Safety-Five Years After the IOM Report, 357 New Eng. J. Med. 2041, 2042-43 (2004); Randall R. Bovbjerg \& Laurence R. Tancredi, Liability Reform Should Make Patients Safer: "Avoidable Classes of Events" Are a Key Improvement, 33 J.L. Med. \& ETHics 478, 478 (2005) ("Half a decade [after To Err Is Human], significant reduction of injury remains a distant prospect, despite some apparent progress."); Lucian L. Leape \& Donald M. Berwick, Five Years After To Err Is Human: What Have We Learned?, 293 JAMA 2384, 2385-90 (2005).

17. See Bovbjerg \& Tancredi, supra note 16 , at 481.

18. See, e.g., Ferdon v. Wis. Patients Comp. Fund, 701 N.W.2d 440 (Wis. 2005); Lucinda M. Finley, The Hidden Victims of Tort Reform: Women, Children, and the Elderly, 53 EMORY L.J. 1263 (2004); David M. Studdert et al., Can the United States Afford a "No-Fault" System of Compensation for Medical Injury?, 60 LAW \& ConTemp. Probs. 1 (Spring 1997). 


\section{A REPORT FROM the Field}

Over the past several years, the medical establishment and various governmental units have considered an array of information-sharing proposals to address the problem of medical error. I was involved in one such effort undertaken by a leading medical reform organization (call it "the MRO") located in a Midwestern community. ${ }^{19}$ The MRO concluded that patient safety was a high-priority concern and that data should be gathered and analyzed to determine if patterns of error might be discovered and protective protocols designed. As has been the case in the literature on reporting, precisely what information should be gathered was a matter of debate. Some thought all errors ought to be recorded and examined, while others thought more would be gained if near-miss events alone were scrutinized. Another source of contention was whether different institutions, including major hospitals and healthcare providers like HMOs, could and should share error data with each other, thereby creating a broader and richer pool for analysis.

My job was to provide legal analysis to the MRO regarding the vulnerability of the data gathered by such error reporting to discovery in litigation. Healthcare professionals found this issue significant because of their apparent deep and abiding anxiety about disclosure and its legal consequences. ${ }^{20}$ The state in which these events took place had legislation extending privilege protection to data gathered and prepared for internal quality control purposes, such as peer review or medical studies. ${ }^{21}$ The contours of the privilege shielding records from disclosure to medical malpractice plaintiffs were not entirely clear. There was a series of judicial decisions granting injured patients access to items, such as HMO documents refusing to approve treatment, informal conversations among medical staff regarding patient injury, and incident reports created during treatment or care. In this unsettled legal environment, there was a great deal of concern about the scope and reliability of the privilege. In a written evaluation, I

19. I have chosen to present this material without identifying characteristics in order to protect the confidences of those who participated in the MRO's work.

20. See Marshall B. Kapp, Medical Error Versus Malpractice, 1 DePaul J. Health Care L. 751, 765 (1997); J. Bryan Sexton et al., Error, Stress, and Teamwork in Medicine and Aviation: Cross Sectional Surveys, 320 Brit. Med. J. 745, 747 (2000) (cited in Melissa Chiang, Note, Promoting Patient Safety: Creating a Workable Reporting System, 18 Y ALE J. ON REg. 383, 396 n.60 (2001)) (stating that $71 \%$ of medical practitioners found acknowledging error to be difficult due to the threat of malpractice suits).

21. See generally William D. Bremer, Scope and Extent of Protection from Disclosure of Medical Peer Review Proceedings Relating to Claim in Medical Malpractice Action, 69 A.L.R. 5th 559 (2004). 
suggested that a program could be designed, however, that was highly likely to assure privilege protection, so long as certain formalities were followed and litigation-related risk management operations were separated from safety-focused medical study activities. ${ }^{22}$

To my surprise, my recommendations were viewed as extremely controversial. Medical professional participants in the MRO found them encouraging, while hospital lawyers in the group were intensely hostile. ${ }^{23}$ The lawyers' concerns were diffuse, but turned on several key points. First and foremost, hospital counsel argued that privileged materials were never truly safe from discovery and that juries provided with such materials would inevitably use them to award huge damages. Second, plaintiffs' lawyers would exploit any reform for their own nefarious purposes. ${ }^{24}$ Third, counsel argued that their insurance coverage arrangements imposed restrictions on data sharing that simply made the proposal impossible. ${ }^{25}$ Finally, the lawyers said that hospital counsel and the associated risk-management teams needed access to all care-related information in order to effectively protect their clients. ${ }^{26}$ It became increasingly clear that the hospital attorneys were in the grips of an irrational fear that could not be assuaged by legal analysis, reason, or program revision. Because counsel were so adamant in their opposition and alarmed by my analysis, they threatened to scuttle any progress in error reporting if my work were relied upon or if I were to continue as a major contributor to the reform project. Subsequently, I was eased out of the effort.

The intensity of this opposition undermined the MRO's patient safety initiative. Progress on error reporting slowed to a crawl, and no system yet exists or will likely be implemented soon. Moreover, if this Article's analysis is correct, the privileged status of error reports in any such system is now in greater jeopardy because of the continued

22. Id. That separation was apparently mandated by the applicable statute and case law.

23. Some data suggest that doctors themselves do not believe that the law will protect the confidentiality of error-reporting materials. Chiang, supra note 20, at $396 \mathrm{n} .61$ (finding that $85 \%$ of healthcare professionals in one non-rigorous online survey doubted that confidentiality protection existed). My experience suggests that this may have more to do with the legal advice provided by hospital, HMO, and insurance company counsel than with health professionals' experiences or personal beliefs.

24. I was identified with plaintiffs' lawyers because I occupy a chair endowed by an eminent plaintiffs' personal injury lawyer.

25 . Insurance contracts generally require the cooperation of the insured in defending claims. It may be argued, albeit unpersuasively, that information sharing betrays that requirement. See Cohen, supra note 15, at 1471-72 (focusing on apology rather than error reporting); Bryan A. Liang, The Adverse Event of Unaddressed Medical Error: Identifying and Filling the Holes in the Health-Care and Legal Systems, 29 J.L. MED. \& ETHICs 346, 353 (2001).

26. On the limited efficacy of risk management, see Liang, supra note 25 , at 348 . 
yoking together of risk management and patient safety initiatives, despite legal requirements that they be separated. One of the most important reasons for the slow pace of patient-safety reform is that the lawyers advising doctors, and the physicians listening to them, apparently embrace a paranoid vision of the legal world. ${ }^{27}$ Behind that vision is the proposition that juries in medical malpractice actions are ready to find against healthcare providers and to award enormous damages on virtually any pretext. This view has two corollaries: first, that plaintiffs' lawyers exploit such jury proclivities for their own venal ends; and second, that insurance companies are properly worried about juries, justifying the barriers they sometimes seek to impose on information sharing and other reforms. In the grips of this juryphobia, any reform that fails to remove courtroom adjudication and jury trials is either doomed to rejection by the medicolegal establishment or will face substantial resistance in implementation.

\section{Juryphobia in the Literature of Patient Safety and Medical Malpractice Reform}

The juryphobia I encountered while working for the MRO is readily visible in the literature advocating patient safety and medical malpractice reform. Unsurprisingly, many contributors to this literature also provide legal advice to the healthcare industry. Fear of juries and the desire to keep records from them dominate the works that urge reporting reform. Commentators have also deployed juryphobic rhetoric to oppose the implementation of various reporting schemes mandated by both state statutes and the national hospital accrediting body, the Joint Commission on Accreditation of Healthcare Organizations (JCAHO). ${ }^{28}$ Virtually all reformers assert that error reporting is impossible unless ironclad guarantees of confidentiality are provided. ${ }^{29}$ Their objective is to establish a walled-off error-reporting universe with complete internal openness, "largely surrounded by an external wall to shut out injured patients and their lawyers." 30

27. That vision extends to other areas as well, such as end-of-life decisions, where some hospital counsel have imposed inappropriate legal constraints on familial and medical decision making. See Norman Fost, Do the Right Thing: Samuel Linares and Defensive Law, 17 LAw, MED. \& Health Care 330 (1989); Marshall B. Kapp, Treating Medical Charts Near the End of Life: How Legal Anxieties Inhibit Good Patient Deaths, 28 U. Tol. L. Rev. 521 (1997).

28. See JCAHO Home Page, http://www.jointcommission.org (last visited Jan. 28, 2008).

29. See, e.g., Johnson \& Shapiro, supra note 5, at 6 ("Perhaps the greatest impediment to the successful implementation of error reduction systems is . . the fundamental question of whether and how reported information can be kept confidential."); accord Bovbjerg \& Tancredi, supra note 16 , at 480 .

30. Bovbjerg \& Tancredi, supra note 16 , at 480. 
Reformers' primary reason for this protective demand is to counter their fear that plaintiffs' attorneys, either through discovery in litigation or other means, like freedom of information requests, will seize the candid and revealing error assessment documents dutifully filed by cooperating doctors, nurses, and other healthcare professionals. ${ }^{31}$ As one commentator picturesquely described healthcare providers' fears, error reports "would attract plaintiff [sic] attorneys as surely as honey attracts bears." 32 This imagery illustrates the healthcare industry's anxieties. Plaintiffs' lawyers are depicted as bears-large and fierce beasts with voracious appetites. The information they seek is analogized to the sweetest, most attractive substance in the ursine world, a commodity bears will do almost anything to get.

According to error-reporting advocates, records seized by members of the plaintiffs' bar will lead to a significantly increased number of malpractice claims filed. ${ }^{33}$ Such reporting systems, like that created by JCAHO, have been described as a "lawsuit kit for attorneys." 34 Reformers contend that, with error-reporting documents in hand, patients and their lawyers will be able to cow doctors, hospitals, and HMOs into settling ever more cases. ${ }^{35}$ Where settlement cannot be achieved, such "smoking gun" documents will persuade juries to find malpractice and award substantial sums. ${ }^{36}$ Some reporting advocates have sought to further their campaign against malpractice liability by strengthening this nightmare scenario with anecdotal horror stories. One example is the case where an error was disclosed when it could easily have been hidden and the result was "a protracted lawsuit." 37 Such a scenario is reminiscent of the campaign against juries, lawyers, and courts by those who repeatedly and inaccurately referenced the case of Stella Liebeck, who was scalded when a cup of McDonald's coffee spilled in her lap. ${ }^{38}$ In both cases, with virtually no supporting data, one is invited to assume that, left to itself, the legal system will produce absurd and unjust results.

When error reporting is mandated and confidentiality is not guaranteed, commentators claim that doctors and other healthcare profes-

31. See Liang \& Small, supra note 13 , at 238.

32. Furrow, supra note 9, at 183.

33. See Liang, supra note 25, at 351; but see Bernard Black et al., Stability, Not Crisis: Medical Malpractice Claim Outcomes in Texas, 1988-2002, 2 J. EMPIRICAL Legal Studies 207 (2005) (finding that, in Texas, numbers of large claims held steady and smaller claims declined).

34. Black et al., supra note 33 , at 351.

35. See Liang \& Small, supra note 13, at 238.

36. Id.

37. Id. at 231-32 n.66.

38. William Haltom \& Michael McCann, Distorting the law: Politics, Media, and The Litigation Crisis 183-226 (2004). 
sionals experience mounting anxiety about their exposure to legal liability. This anxiety chills medical personnels' willingness to file any reports at all. Richard Davidson, once President of the American Hospital Association (AHA), relied upon this argument when he declared that reporting is "not possible if some plaintiff's attorney is climbing on your back." 39 Where reporting has been mandated, underreporting is common. ${ }^{40}$ The same has been true with respect to both the JCAHO and the Veterans Administration's (VA) reporting systems. ${ }^{41}$ In all of these cases, reform advocates claim that uncertainty about access to, or use of, reports has impeded cooperation. ${ }^{42}$ Some medical malpractice reformers believe that the situation was not always this way and that justified distrust of juries, lawyers, and courts is rising and "transforming healthcare." 43 In this view, which seems to harken back to a lost golden era, doctors have become so fearful that they shy away from making records of any sort. ${ }^{44}$

Recently, a movement has arisen championing the idea that doctors and hospitals should apologize to patients whom they have harmed. ${ }^{45}$ Those who urge disclosure of information about injurious errors argue that patients have a therapeutic and moral claim to be informed about medical mistakes and treatment-related injuries. ${ }^{46}$ Only properly informed patients can address their injuries through treatment, let alone consider legal remedies. The American Medical Association (AMA) and the AHA both concluded that physicians' ethical responsibilities include informing patients of iatrogenic injuries. ${ }^{47}$ Those who suggest

39. Chiang, supra note 20, at 391 (citing Robert Pear, Clinton to Order Steps to Reduce Medical Mistakes, N.Y. TImes, Feb. 22, 2000, at A1).

40. See id. at 393 ("[I]n Pennsylvania, which requires reports for gross events such as deaths due to injuries, suicide, [or] malnutrition, the Department of Health received only one report for the one-year period that ended in June 1999.").

41. See Furrow, supra note 9, at 208; David A. Hyman \& Charles Silver, Believing Six Improbable Things: Medical Malpractice and "Legal Fear," 28 HARv. J.L. \& PuB. PoL'y 107, 110 (2004).

42. See supra notes $28-38$ and accompanying text.

43. See Troyen A. Brennan \& Philip K. Howard, Heal the Law, Then Health Care, WASH. PosT, Jan. 25, 2004, at B7.

44. $I d$.

45. See Jonathan R. Cohen, Advising Clients to Apologize, 72 S. CAL. L. Rev. 1009 (1999); Aviva Orenstein, Apology Excepted: Incorporating a Feminist Analysis into Evidence Policy Where You Would Least Expect It, 28 Sw. U. L. Rev. 221 (1999); but see Lee Taft, Apology Subverted: The Commodification of Apology, 109 Y ALE L.J. 1135 (2000).

46. See Bovbjerg \& Tancredi, supra note 16, at 482; Cohen, supra note 15, at 1477.

47. See Bovbjerg \& Tancredi, supra note 16, at 482. The AMA has stated that doctors have an ethical duty to "at all times deal honestly and openly with patients" and provide them "all the facts necessary to ensure understanding of what has occurred," so that they will "be able to make informed decisions regarding future medical care." Id. 
that medical providers should apologize for injuries they have caused argue that patients deserve the respect and contrition of an apology. ${ }^{48}$

Despite the powerful medical and moral appeal of providing patients with information and, if appropriate, an apology, substantial resistance to both exists in the medical industry. Again, reformers lay most of the blame on the legal system. Some assert that doctors phrase everything exceedingly carefully because of their fear of being sued after admitting errors to patients. ${ }^{49}$ Physicians will often say nothing at all even if candor would best serve their patients' interests. ${ }^{50}$ Reformers claim that disclosure will likely result in a traumatic and debilitating lawsuit. ${ }^{51}$ Similar to the case of reporting, reformers claim that plaintiffs' lawyers lurk in the shadows, ready to pounce on any admission. ${ }^{52}$ The natural and predictable result, so the argument goes, is that doctors and other caregivers feel a chill that leads them to adopt a policy of silence. ${ }^{53}$

Apology first gained serious attention among reformists in 1987 when the VA hospital in Lexington, Kentucky adopted an innovative program responding to acts of medical malpractice by its staff. ${ }^{54}$ As soon as the VA hospital discovered an injurious medical error to a patient, it would contact that patient or her surrogate, apologize for the error, advise the patient to obtain the assistance of counsel, and offer monetary compensation or other corrective action. ${ }^{55}$ The program was remarkably successful, particularly in boosting staff morale, reducing patients' suspicions and hostilities, and reducing the hospital's overall expenditures on medical malpractice claims. ${ }^{56}$

This program of candid disclosure, apology, and compensation seemingly contradicts juryphobia; however, much of the apology literature has carefully distinguished the situation at the VA from other healthcare settings. Reformists argue that these differences doom apology to failure outside the VA system unless broad confidentiality protections are extended to apologizing doctors and hospitals. ${ }^{57}$

\footnotetext{
48. See Taft, supra note 45 , at 1160.

49. Bovbjerg \& Tancredi, supra note 16 , at 482.

50. See Cohen, supra note 15 , at 1011.

51. See Rachel Zimmerman, Doctors' New Tool to Fight Lawsuits: Saying 'I'm Sorry, W ALL St. J., May 18, 2004, at A1; Randall R. Bovbjerg, Patient Safety and Physician Silence, 25 J. Legal Med. 505 (2004).

52. See Bovbjerg, supra note 16 , at 482.

53. See id.

54. See Cohen, supra note 15, at 1447-59; Steve S. Kraman \& Ginny Hamm, Risk Management: Extreme Honesty May Be the Best Policy, 131 Annals of Internal Med. 963 (1999).

55. See Cohen, supra note 15, at 1449-50; Kraman \& Hamm, supra note 54, at 966-67.

56. See Cohen, supra note 15 , at 1473-74.

57. See id. at 1463-64 n.68.
} 
Again, the villains of the reformers' analyses are lawyers and jurors, who are eager to slam any healthcare provider that apologizes. ${ }^{58} \mathrm{Re}$ form advocates argue that the VA program works for several reasons: federal law requires that all claims be heard by a judge rather than a jury; no claimant can be awarded punitive damages; VA physicians, who are employees of the federal government, are not generally subject to suit as individuals; and these physicians, because of their positions as government employees, are not tied to the vagaries of maintaining private malpractice insurance. ${ }^{59}$ These arrangements make for a setting in which the menace from juries and lawyers has been largely neutralized. Without such neutralization, apology is allegedly impossible.

Nationwide, those boosting apology have rallied around the idea that confidentiality is key. To this end, they have promoted legislation that bars any judicial consideration of apology or of "benevolent gestures."60 Perhaps the high-water mark of this effort is the following Colorado statute:

In any civil action brought by an alleged victim of an unanticipated outcome of medical care, or in any arbitration proceeding related to such civil action, any and all statements, affirmations, gestures, or conduct expressing apology, fault, sympathy, commiseration, condolence, compassion, or a general sense of benevolence which are made by a health care provider or an employee of a health care provider to the alleged victim, a relative of the alleged victim, or a representative of the alleged victim and which relate to the discomfort, pain, suffering, injury, or death of the alleged victim as the result of the unanticipated outcome of medical care shall be inadmissible as evidence of an admission of liability or as evidence of an admission against interest. ${ }^{61}$

The scope of this exclusion is remarkably broader than the protection granted by most other states. ${ }^{62}$ One must wonder whether the point of apology - a statement accepting responsibility for an offense-has been absolutely vitiated in the effort to prevent jury consideration of a caregiver's words. ${ }^{63}$

58. See Aaron lazare, On Apology 20 (2004).

59. See Cohen, supra note 15 , at 1455-56.

60. Bovbjerg \& Tancredi, supra note 16, at 482; accord Jonathan R. Cohen, Legislating Apology: The Pros and Cons, 70 U. CIN. L. REv. 819 (2002) (assessing the positive and negative impacts of apology legislation).

61. Colo. Rev. Stat. Ann. \$13-25-135(1) (West 2005).

62. See, e.g., Mass Gen. Laws Ann. ch. 233, § $23 \mathrm{D}$ (West Supp. 2007); Cal. Evid. Code $\$ 1160$ (a) (West Supp. 2007) (both statutes focus on "benevolent" gestures and remarks rather than admissions of liability).

63. See LAzARE, supra note 58, at 23; Jennifer K. Robbennolt, Apologies and Legal Settlement: An Empirical Examination, 102 Mich. L. Rev. 460, 468-69 (2003). 
Not surprisingly, juryphobia not only surfaces in discussions about error reporting and apology, but also in healthcare professionals' discussions of the merits of the medical malpractice system. In the latter context, juryphobia does not squelch reforms, but instead energizes calls for change. Some claim, with minimal empirical justification, that there are many grave defects in the malpractice system, particularly in the work of juries. Jury trial is deemed extremely inefficient, costly, ${ }^{64}$ and exceedingly inaccurate in determining liability. ${ }^{65} \mathrm{Be}-$ cause courts conduct jury trials in only a small percentage of malpractice cases, reformers equate trials with a lottery and say that the "threat" of using them is extortionate. ${ }^{66}$ To remove doctors from this fearsome lottery, some reformers argue that only hospitals, HMOs, and other organized entities should be amenable to suit and that enterprise liability should replace the individual tort exposure of medical personnel. ${ }^{67}$ This solution frees individual physicians from suit, but is viewed by some as not going far enough. Many reformers urge more thoroughgoing solutions that either substitute nonjudicial forums for court procedures or remove malpractice claims from judges' and juries' scrutiny and place them before private arbitrators and mediators. ${ }^{68}$ Such private proceedings maintain secrecy and, reformers presume, would result in rulings far less critical of the medical profession. ${ }^{69}$

\section{Unanswered Questions and Unsupported Assumptions IN THE REFORMIST LITERATURE}

Medical malpractice literature is littered with untested assumptions about the behavior of medical professionals, patients, and juries. Some of these assumptions are critical to the policy steps urged by reformers and cry out for empirical examination. If they are well founded, the case for change is significantly strengthened. However, if they are unsupported, reformers' proposals would seem to require serious reexamination and perhaps even modification.

\footnotetext{
64. See Myers, supra note 14, at 264.

65. See Liang, supra note 25, at 349.

66. See Brennan \& Howard, supra note 43.

67. See Kenneth S. Abraham \& Paul C. Weiler, Enterprise Medical Liability and the Evolution of the American Health Care System, 108 HARv. L. Rev. 381 (1994); Myers, supra note 14, at $274-77$.

68. See Liang \& Small, supra note 13, at 238-42 (promoting mediation as an alternative to litigation). Newt Gingrich, Speaker of the House of Representatives for the U.S. Congress from 1995 to 1999, proposed a new "health-court system" in which the majority of judges would have medical, rather than legal, training. Alan Feigenbaum, Special Juries: Deterring Spurious Medical Malpractice Litigation in State Courts, 24 Cardozo L. Rev. 1361, 1419 (2003).

69. See Liang, supra note 25 , at $359-60$.
} 


\section{A. Error Reporting}

In error-reporting and doctor-patient communication regarding iatrogenic injuries, there are at least three critical assumptions that warrant social science scrutiny. The first is that medical malpractice claims stifle the amount of injury-related information provided by medical personnel. The second is that patients will be inclined to sue if provided with information about medical errors in their treatment. The third is that juries will react negatively if informed of medical workers' error reports or comments to injured patients.

Based on the vehemence of the reformers' assertions about the chilling effect of litigation, it is logical to assume that reporting, either to error systems or patients, is powerfully influenced by medical malpractice activity. There are, however, reasons to doubt this core assumption. Resistance to reporting is apparently not a new phenomenon. In fact, there are grounds to believe that medical professionals have long been close-mouthed about errors. ${ }^{70}$ Medical culture emphasizes perfection and ostracizes those who do not achieve it. ${ }^{71}$ These views are grounded in professional attitudes and assessments and, arguably, are at the root of the nonreporting problem. ${ }^{72}$ In other words, the medical world's silence about its mistakes may be the product of forces and views within medicine, rather than a response to intrusions of the legal system. Courts eventually compelled doctors to provide patients with more information about the risks of, and alternatives to, treatment through the informed consent doctrine. The tortuous history of this doctrine suggests that a significant number of doctors are not inclined to freely share information, pretreatment or later, and that legal or other societal interventions are necessary to break down medically manufactured walls of silence. ${ }^{73}$ The impact of medical culture and attitudes deserves close scrutiny before juryphobic concerns are blamed for nonreporting.

Whatever one concludes about the impact of medical culture, the influence of legal activity on the rate of error reporting in the healthcare industry should be examined. There are probably multiple causes for medical silence, and the threat of legal scrutiny may be one of them. An empirical assessment of the influence of a reasonably reliable promise of confidentiality on the rate of error reporting would help policymakers determine whether removing the threat of legal scrutiny boosts the willingness to report. Unfortunately, little data on

70. See Furrow, supra note 9, at 185-89; Hyman \& Silver, supra note 41, at 112.

71. See Hyman \& Silver, supra note 4, at 898-99; Myers, supra note 14, at 261-62.

72. See supra notes 70-71 and accompanying text.

73. See, e.g., Canterbury v. Spence, 464 F.2d 772 (D.C. Cir. 1972). 
the question exist. ${ }^{74}$ One of the few studies available found that there was virtually no difference in reporting rates between systems that offered confidentiality and those that did not. ${ }^{75}$ In both cases, massive underreporting was common. ${ }^{76}$ While this evidence is not definitive, other information suggests that lawsuits are not a central factor in the medical profession's reporting decisions. For example, the British define medical malpractice litigation fairly narrowly, yet error reporting is less frequent in the United Kingdom than in the United States, where malpractice dockets are relatively large. ${ }^{77}$ In America, doctors specializing in certain areas of medical practice, like obstetrics, are far more likely to be sued than those in other specialties. ${ }^{78}$ In none of the less litigious specialties, however, is reporting more robust. ${ }^{79}$ There may be a number of explanations for these phenomena, but they certainly reinforce doubts about the causal link between litigation and resistance to reporting.

At least one other point raises questions about the reformers' hypothesized connection between malpractice litigation and reporting. Beginning in the mid-1980s, anesthesiologists faced rising error rates and sky-rocketing insurance premiums. ${ }^{80}$ Through a concerted program of training, equipment redesign, and reporting, the anesthesiology specialty drove down the error rate dramatically. ${ }^{81}$ This was accomplished despite aggressive efforts by the plaintiffs' bar to bring and win medical malpractice claims. Similar results have been reported elsewhere, including emergency room care, the provision of transfusions, and the dispensing of prescription medication. ${ }^{82}$ Reporting has led to significant improvements in safety, notwithstanding substantial litigation. All this casts doubt on the assertions that confidentiality plays a key role in safety improvement or even in error reporting. To answer questions posed by these facts, careful study is warranted.

74. See Chiang, supra note 20 , at 396 ("The number of studies investigating the problem of underreporting is small and their sample sizes are smaller."); Furrow, supra note 9, at 203.

75. See Furrow, supra note 9, at 203 \& n.162 (citing State Reporting of Medical Errors and Adverse Events: Results of a 50-State Survey, Executive Summary, available at http://www.nashp. org/_docdisp_page.cfm?LID=0560704C-4CAC-11D6-BCEE00A0CC558925).

76. Id. at 203 .

77. See Hyman \& Silver, supra note 41 , at 111.

78. Michael Klaus, Outsourcing Vital Operations: What if U.S. Health Care Costs Drive Patients Overseas for Surgery?, 9 QuinNiPIAC HeAlTH L.J. 219, 230 (2006).

79. Maxwell J. Mehlman, Dishonest Medical Mistakes, 59 VAND. L. Rev. 1137, 1139-40 (2006).

80. See Johnson \& Shapiro, supra note 5, at 4; Myers, supra note 14, at 266.

81. See Johnson \& Shapiro, supra note 5, at 4-5; Myers, supra note 14, at 266; see also Barach, supra note 2 , at $19 \& \mathrm{n} .75$.

82. See supra note 81 and accompanying text. 
One key analogy reformers have relied upon to justify their calls for confidentiality involves the aviation industry, in which a confidential near-miss reporting system has been in operation for many years. ${ }^{83}$ No one using the system is called to account for the contents of a report. In fact, the only way to get into trouble is to fail to report a near-miss incident when others do so. ${ }^{84}$ Submitted reports are analyzed and often lead to directives designed to enhance safety. ${ }^{85}$ While the aviation model has appeal, several points suggest caution is necessary before concluding that an essentially identical system is warranted in medicine. In the aviation industry, all crashes are thoroughly investigated by the National Transportation Safety Board (NTSB). ${ }^{86}$ The NTSB's work is not confidential and may be utilized by litigants. ${ }^{87}$ Tort doctrines, like res ipsa loquitur, make liability findings a near certainty in commercial aviation cases. ${ }^{88}$ When an airliner goes down, victims are virtually always compensated. The key concerns are how much will be paid and by whom. This should be contrasted with medical malpractice litigation, where causation and liability are often hotly contested and there is no definitive assessment of the sort provided by the NTSB. The legal landscape in these two areas is so different that one must wonder whether the aviation experience has much to teach us about medical error reporting.

The juryphobic hypothesis is that unprotected communications admitting error-especially admissions to patients-will increase the volume of litigation. At the outset, it should be noted that the level of malpractice claiming in America is far below the level of injury, raising significant doubts about the litigiousness of American patients. ${ }^{89}$

83. See Barach, supra note 2, at 20-21.

84. Id.

85. Linda J. Connell, Cross-Industry Applications of a Confidential Reporting MODEL, http://asrs.arc.nasa.gov/docs/rs/62_Cross $\% 20$ Industry $\% 20$ Applications $\% 200$ \% $20 \mathrm{Re}$ porting \%20Model.pdf (last visited Jan. 29, 2008).

86. See Aviation Attorney Blog, http://www.aviationattorneyblog.com/page/3 (last visited Jan. 29, 2008).

87. See Trowbridge Littleton, The National Transportation Safety Board: How Should They Conduct Witness Investigations-The Need for a Privilege, 27 TransP. L.J. 255 (2000):

After an aircraft accident there is a civil trial for damages. In most cases these suits are brought many months if not years after the accident has occurred. In an effort to obtain the best information available on the accident, litigants routinely move, under the Freedom of Information Act, to get the reports of the NTSB.

Additionally, in most circumstance [sic], the Factual Report (which contains the Field

Notes) is admissible at trial under the public documents exception to the hearsay rule. Id. at 261 .

88. Prosser and Keeton on the Law of Torts $\$ 39$, at 246-47 (W. Page Keeton et al. eds., 5th ed. 1984).

89. See To Err is Human, supra note 1; Lori Andrews, Studying Medical Error In Situ: Implications for Malpractice Law and Policy, 54 DePAUL L. REv. 357, 370 (2005) (finding that 13 of 
The idea that large numbers of previously docile but injured patients will rise up in response to error reports may exaggerate the influence of such reports. Putting that aside, studies suggest that patients appreciate candor about medical errors and that such communication both reduces patients' inclinations to sue their doctors and makes caregivers seem more human and sympathetic to their injured patients. ${ }^{90}$ Suits grow in number when doctors appear dishonest, arrogant, or unconcerned about the consequences and implications of their mistakes. ${ }^{91}$ While lawsuits-especially those concerning serious injuries-are unlikely to disappear because of error reporting, the patient reaction data cast doubt upon the hypothesis that reporting without confidentiality is legal suicide. ${ }^{92}$ More research is clearly warranted to assess patients' reactions to reform.

It is an article of the reformist faith that juries exposed to error reports will be more inclined to find against caregivers in medical malpractice cases. Reformers advance numerous theoretical bases for that contention. Some claim that error reports and similar statements will trigger the "hindsight bias" of the jury. ${ }^{93}$ Hindsight bias has been observed in the deliberations of juries that are asked to determine the before-the-fact (ex ante) reasonableness of a course of conduct resulting in injury. ${ }^{94}$ The usual source of hindsight bias is the fact of the injury. In such cases, the injury is "read back" into the preceding circumstances to suggest that the defendant knew, or should have known, that his actions were unreasonably risky. ${ }^{95}$ Hindsight bias is a serious problem in some negligence cases and in cases where questionable business decisions are reviewed. ${ }^{96}$ In the context of error reporting, however, its relevance may be questioned. Error reports declare medical mistakes; they do not, however, suggest medical foreknowledge or unreasonableness ex ante. The complained of injury in a case may provoke hindsight bias, but it is less clear that an ex post

1,047 patients who suffered medical errors brought claims); Hyman \& Silver, supra note 41, at 116; Studdert et al., supra note 18 , at 17.

90. See Bovbjerg \& Tancredi, supra note 16 , at 482,497 n. 79 ; Myers, supra note 14 , at 278 \& n.224.

91. See supra note 90 and accompanying text

92. See Bovbjerg \& Tancredi, supra note 16, at 482, 497 n.79; Myers, supra note 14 , at 278 \& n.224.

93. See Liang \& Small, supra note 13 , at 229.

94. See Jonathan D. Casper et al., Juror Decision Making, Attitudes, and the Hindsight Bias, 13 Law \& Hum. Behav. 291 (1989); Kim A. Kamin \& Jeffrey J. Rachlinski, Ex Post $\neq$ Ex Ante: Determining Liability in Hindsight, 19 LAw \& Hum. BeHAv, 89 (1995); Susan J. LaBine \& Gary LaBine, Determinations of Negligence and the Hindsight Bias, 20 Law \& Hum. BeHav. 501 (1996).

95. See supra note 94 and accompanying text.

96. Id. 
report enhances the bias already triggered by the facts. Thus, such reports require further empirical scrutiny before reformers can conclude that they heighten hindsight bias.

Error reports are admissions of mistakes. They resemble confessions or inculpatory statements in criminal cases. The U.S. Supreme Court has held that confessions are so influential when wrongfully admitted that they destroy the jury's ability to dispassionately consider the defendant's innocence. ${ }^{97}$ Psychological examination has tended to confirm the power of confessions and the risk they pose to decisionmakers. ${ }^{98}$ If error reports work like confessions, they may seriously endanger the fairness of fact finding in medical malpractice actions. Unfortunately, this hypothesis is untested, and there are different sorts of error reports containing different types of information.

If confidentiality is to be justified, a robust program that empirically assesses the impacts of error report and error admission evidence in malpractice cases would be useful. The first question is whether jurors will understand how to use error reports and admissions. All error reports are not created equal. Some will clearly document errors amounting to malpractice, others will show mistakes that are legally defensible, and still others will be entirely irrelevant to the legal issues surrounding a patient's injury. In addition, certain reporting systems will only describe near misses, which, by definition, have not led to harm. Whether jurors can successfully distinguish between these different error documents and use them appropriately presents an important question. The risk of unfounded verdicts is substantially reduced if jurors can appropriately discriminate between different kinds of error documents.

A second question concerns the impact that relevant error report documents will have on cases in which they are used. Will such documents function like confessions, overwhelming other evidence? Will they dictate liability even when causation is unclear? Will they boost jury awards? On one hand, admissions of error may be perceived as honorable efforts to improve medical care. In that case, jurors' reactions may mirror patients' reactions, and doctors may be viewed more sympathetically, which might ultimately reduce awards. Alternatively, if error information has been suppressed or defendants absolutely deny liability, the introduction of error reports may be seen as revealing a smoking gun that justifies a large verdict, especially because

97. See Jackson v. Denno, 378 U.S. 368 (1964).

98. See Saul M. Kassin \& Lawrence S. Wrightsman, The american Jury on Trial: Psychological Perspectives 86-93 (1988). 
the defendants' conduct looks like a cover-up. ${ }^{99}$ Many more questions deserve examination. The challenge is to design simulation experiments that yield broadly applicable data.

\section{B. Apology}

Questions raised by the apology literature are similar to those considered with respect to reporting. The medical culture that has fostered silence rather than reporting has also restrained apology. There was little medical literature advocating apology until the last decade, and erring doctors and other healthcare professionals have never routinely provided apologies. ${ }^{100}$ Again, the problem may be traced to attitudes within the medical profession, rather than litigation's pernicious influence. Nevertheless, the questions remain whether litigation concerns have significantly increased the fear of apology and whether the present legal climate makes reform more difficult. There is so litthe information available that it is impossible to answer such questions. However, if apology works like error reporting, it is reasonable to suggest that malpractice litigation rates will scarcely be influenced by the frequency of apology.101

Regarding the question of patient reaction to apology, the most useful information comes from the analogous error-reporting studies. These studies suggest that a significant number of patients will react positively to apology, as they do to an admission of error. ${ }^{102}$ Many patients are likely to view an apology as a caregiver's effort at honesty. ${ }^{103}$ Perceived lack of candor is a key determinant in patients' decisions to sue. ${ }^{104} \mathrm{~A}$ proper apology may dissuade a substantial number of patients from litigating. ${ }^{105}$ It is unclear, however, whether all sorts of apologies will similarly affect patients. ${ }^{106}$ Theoretically, a

99. See Brian H. Bornstein et al., The Effects of Defendant Remorse on Mock Juror Decisions in a Malpractice Case, 20 BeHAV. SCI. \& LAw 393 (2002) (noting the varied impact of apology on awards based on the timing of the apology).

100. See Lazare, supra note 58, at 98; Ninth Annual Stein Center Symposium, The Role of Forgiveness in the Law, 27 FordHAM URB. L.J. 1347, 1426 (2000).

101. Brian Bornstein, in communications with the author, has suggested that adopting laws to protect apology raises similar empirical questions about physician awareness of legal change and the effect, if any, on the rate and finality of apology.

102. Thomas H. Gallagher et al., Patients' and Physicians' Attitudes Regarding the Disclosure of Medical Errors, 289 JAMA 1001 (2003).

103. Amy B. Witman et al., How Do Patients Want Physicians to Handle Mistakes? A Survey of Internal Medicine Patients in an Academic Setting, 156 Archives of INTERnal Med. 2565, 2566 (1996).

104. Charles Vincent et al., Why Do People Sue Doctors? A Study of Patients and Relatives Taking Legal Action, 343 LANCET 1609, 1612 (1994).

105. See LAzARE, supra note 58, at 173 .

106. See Robbennolt, supra note 63. 
vague or general apology will be less effective than a specific one. For example, an apology from a hospital's chief of staff will be less powerful than one from the medical professional who made the mistake. Likewise, an apology that does not offer compensation will be less influential than one that does. These matters merit empirical scrutiny. ${ }^{107}$

A central issue, equally relevant to apology and error reporting, is how jurors will use information acknowledging mistakes in determining liability and fixing damages in malpractice litigation. Are jurors capable of making the fine distinctions necessary to interpret varying sorts of caregiver remarks? Much legislation in the apology area differentiates "benevolent gestures" from apologies. Benevolent gestures-statements voicing sympathy, commiseration, or compassionare most frequently classified as confidential. ${ }^{108}$ Whether jurors can recognize this distinction and act accordingly presents an interesting question. ${ }^{109}$

Assuming that a full-blown apology is made, the next issue to be determined is its impact on a liability finding and on the amount awarded in damages. One might reasonably anticipate that an apology will moderate an award because of the positive feelings a medical professional's candor will likely generate. ${ }^{110}$ Currently, however, scholars have little data in the area and none concerning liability. ${ }^{111}$ If apology were found to cut liability determinations and damage amounts, states barring legal consideration of such materials may cause a boomerang effect that raises awards by excluding evidence of caregivers' contrition. One might argue that the Colorado statute quoted above has this effect unless judges read it to only bar plaintiffs from using apologies to establish liability rather than barring all litigants from referencing any apology that is "an admission of liability." The impact of apology on settlement discussions also merits examination. Whether settlements grow in number or size because of apologies seems an open question. ${ }^{112}$

Some of the reform literature has discussed the "strategic" use of apology - the calculated deployment of apology to forestall suits or

\footnotetext{
107. Id.

108. See supra note 62 and accompanying text.

109. See Robbennolt, supra note 63 , at 470.

110. See Bornstein et al., supra note 99; Robbennolt, supra note 63, at 464 n.17.

111. Robbennolt, supra note 63, at 465 n.19.

112. Id. at $485-86$.
} 
reduce damages. ${ }^{113}$ Will such strategies work, or will juries and patients react to them as they do to dishonest or dissembling behavior? Further, does it matter when an apology is made? One expects that sooner is better, but the question is open. ${ }^{114}$ The matter takes on added salience when one considers a lawyer advising a doctor to apologize at trial, or at some other point during legal proceedings, in an effort to lessen the risk of a large damage award.

\section{Steps Short of Scrapping the Jury Trial}

If researchers determined that jurors are prone to misuse error-reporting data, there are a number of steps that might be taken to reduce the problem without placing burdensome restrictions on the trial process. The first is to collect only near-miss data. Such an approach would, by definition, not gather material regarding injurious events and would, in the vast majority of cases, not produce information relevant to medical malpractice litigation. ${ }^{115}$ Near-miss reporting's irrelevance would make it far less likely to be subject to litigation-driven discovery. This effect may be strengthened if the data submitted are "deidentified" subsequent to filing. ${ }^{116}$ Because there is significant value in dialogue at the time reports are submitted, anonymous filings would seem inferior to reports that indicate the identity of the filer. ${ }^{117}$ Once follow-up questions and clarifications have been completed, however, the utility of identified information is probably outweighed by the value of confidentiality so that identifying information ought to be purged. As a further measure of insulation, error report data might be aggregated so that individual incidents are melded into an overall picture for safety diagnosis but disconnected from any particular patient or claim. These points do not directly affect patient safety, but provide approaches that may facilitate and encourage healthcare industry use of reporting systems.

For obvious reasons, record-keeping solutions will not work with respect to error reports provided to injured patients and apologies. If courtroom use of such materials poses a real threat to safety reporting, then a number of in-court responses are possible. Over the last thirty years, courts and psychologists have developed a series of pro-

113. For a description of the Toro Company's seemingly strategic use of apology techniques to reduce its liability for injuries suffered using its mowers and other lawn care products, see Cohen, supra note 15 , at 1460-62.

114. Bornstein et al., supra note 99; Robbennolt, supra note 63, at 467 n.25.

115. See Barach, supra note 2, at 16-17.

116. See Johnson \& Shapiro, supra note 5, at 9-10.

117. Id. 
tective interventions to deal with eyewitness testimony-evidence that jurors sometimes overvalue. ${ }^{118}$ Courts seldom bar such material but have a process for guarding against its misuse. ${ }^{119}$ The three responses that are most frequently permitted are vigorous cross-examination of the eyewitness (the response traditionally relied upon), the use of expert testimony to describe potential flaws in eyewitness testimony, and limiting instructions designed to caution jurors against excessive reliance on certain eyewitness material. ${ }^{120}$ These approaches, though imperfect, have been demonstrably helpful. ${ }^{121}$ Evaluating the utility of these tools in the error-reporting and apology contexts seems appropriate, particularly if such statements prove overly persuasive to jurors.

If error reporting or apologies are found to inordinately influence juries despite these interventions, it may be worth classifying them as confidential and prohibiting them in the courtroom. The choice to "blindfold" jurors should be viewed as a last resort. Shari Diamond and her colleagues have identified a number of problems that arise with blindfolding, particularly the possibility that jurors will make erroneous factual assumptions absent accurate information about potentially influential topics. ${ }^{122}$ The result of embargoing the topic of insurance coverage illustrates Diamond's point. Blindfolded jurors still think and talk about the existence of insurance. ${ }^{123}$ Failing to address insurance has not made juries more reliable but rather less amenable to court supervision and direction. The analogy between problems with insurance and error reports or apologies is imperfect, but, if it is shown that such materials can bias juror attitudes, policymakers should consider blindfold regulations.

\section{AFTERWORD}

There is substantial evidence that medical culture on its own produced the environment in which errors are not reported, information is not shared, and apologies are not made. It is striking that reformers

118. See Valerie P. Hans \& Neil Vidmar, Judging the Jury 127-28 (1986).

119. See Richard A. Wise et al., A Tripartite Solution to Eyewitness Error, 97 J. CRIM. L. \& Criminology 807, 827-35 (2007).

120. See Wallace D. Loh, Social Research in the Judicial Process: Cases, ReadINGS, AND Text 549-600 (1984); Steven Penrod \& Brian Cutler, Witness Confidence and Witness Accuracy: Assessing Their Forensic Relation, 1 Psychol. PuB. PoL'y \& L. 817 (1995).

121. See Wise et al., supra note 119.

122. See Shari Seidman Diamond \& Jonathan D. Casper, Blindfolding the Jury to Verdict Consequences: Damages, Experts, and the Civil Jury, 26 Law \& Soc'y REv. 513 (1992).

123. See Shari Seidman Diamond \& Neil Vidmar, Jury Room Ruminations on Forbidden Topics, 87 VA. L. REV. 1857 (2001). 
spend so much time and effort on litigation questions rather than on problems posed by medical attitudes and culture. It is possible to see this as blaming the victims for complaining about malpractice. Adopting a policy of secrecy vis-à-vis the courts is a troubling step, especially when the medical profession has not displayed willingness to self-organize and accept responsibility for errors. Instead, it has fought with all its might to cap the damages awarded to children and elderly seriously injured by malpractice. The motive for this approach to malpractice does not seem to be improvement of care, but rather protection of the bottom line. On a number of prior occasions, medicine has had to be pushed to adopt changes beneficial to patients. This was the case with respect to informed consent. Perhaps society needs to push once again. Learned Hand, in the case of the T.J. Hooper, ${ }^{124}$ decided that the well-settled custom of an industry had to yield to the safety interests of society at large. Before such a step is taken, however, we need more data about the behavior of caregivers, patients, and juries. 
